\title{
PENGARUH KUALITAS PRODUK DAN PELAYANAN TERHADAP KEPUTUSAN MENJADI NASABAH DI BANK MUAMALAT CABANG SORONG
}

\author{
${ }^{1}$ Dini Ratna Sari, ${ }^{2 *}$ Wisang Candra Bintari, ${ }^{3}$ Nur Aeni Waly \\ Universitas Muhammadiyah Sorong, Indonesia \\ *binaricandra@gmail.com
}

\begin{abstract}
Abstrak
Penelitian ini bertujuan untuk mengetahui pengaruh kualitas produk, pelayanan terhadap keputusan menjadi nasabah Bank Muamalat Cabang Sorong. Data penelitian ini diperoleh dari kuesioner (primer) yang dibagikan kepada nasabah Bank Muamalat Cabang Sorong. Teknik pengampilan sampel yang digunakan dalam penelitian ini adalah purposive samping dengan jumlah sampel sebanyak 44 Nasabah. Teknik pengumpulan data berupa Obsevasi atau pengamatan secara langung, Kuesioner dan Dokumentasi.Teknik analisis data yang digunakan adalah analisis regresi liniear berganda. Hasil penelitian menunjukkan bahwa: 1) Terdapat pengaruh positif dan signifikan Kualitas Produk terhadap Keputusan Menjadi Nasabah.Hal ini ditunjukkan dengan nilai t hitung sebesar 8,303 dan signifikansi 0,000 <0,05), 2) Terdapat Pengaruh Pelayanan terhadap Keputusan Menjadi Nasabah. Hal ini di tunjukkan dengan nilai t hitung sebesar 1,857 dan signifikansi 0,000 <0,05, 3) Terdapat Pengaruh Kualitas Produk dan Pelayanan secara simultan Terhadap Keputusan Menjadi Nasabah. Hal ini di tunjukkan dengan nila F hitung sebesar 91,704 dan signifikansi 0,000<0,05 Koefisien determinasi (R2) sebesar 0,817 atau 81,7\%.
\end{abstract}

Kata Kunci: Kualitas Produk, Pelayanan, Keputusan Menjadi Nasabah

Abstract
This study aims to see the effect of product influence, decision criteria to become a customer of Bank Muamalat Sorong Branch. The research data were obtained from questionnaires (primary) which were taken to customers of Bank Muamalat, Sorong Branch. The sampling technique used in this study was purposive sampling with a total sample of 44 customers. Data techniques in the form of direct observation or observation, questionnaires and documentation. The data analysis technique used is multiple linear regression analysis. The results showed that: 1) There is a positive and significant effect of Product Quality on the Decision to Become a Customer. This is indicated by the t value of 8.303 and a significance of $0.000<0.05), 2)$ There is an effect of service on the decision to become a customer. This is indicated by the tvalue of 1.857 and a significance of 0.000 $<0.05,3)$ There is a simultaneous effect of product and service quality on the decision to become a customer. This is indicated by the calculated $F$ value of 91.704 and a significance of $0.000<0.05$. The coefficient of determination (R2) is 0.817 or $81.7 \%$.

Key Word: Product Quality, Service, Customer Decision

\section{PENDAHULUAN}

Sektor perbankan sangat strategis perannya dalam memajukan perekonomian masyarakat. Bank mempunyai peran terutama dalam hal menghimpun dana dari masyarakat. Dana yang terhimpun di bank disalurkan kepada masyarakat yang membutuhkan untuk proses produksi barang dan jasa. Lebih dari itu, selain produk meningkat, belanja barang juga meningkat yang secara ekonomi makro akan member kontribusi bagi peningkatan pendapatan nasional (Dibyantoro, 2012).

Menurut Etta Mamang Sangadji dan Sopiah dalam bukunya yang berjudul Perilaku Konsumen menyebutkan ada tiga faktor utama yang mempengaruhi konsumen dalam mengambil keputusan, yaitu: factor psikologis, faktor situasional dan factor sosial. Secara umum nasabah memiliki lima tahap untuk mencapai keputusan pembelian dan hasilnya yaitu 
tahap pengenalan masalah, tahap pencarian informasi, tahap evaluasi alternatif atau pilihan, tahap pilihan (keputusan) dan yang terakhir tahap perilaku pembelian.3 Keputusan (decision) berarti pilihan (choice) yaitu pilihan dari dua atau lebih kemungkinan. Sebagian besar keputusan berada pada satu dari dua kategori: terpogram dan tidak terpogram. Hal ini menunjukkan bahwa keputusan bias dikatakan sama dengan pilihan, ada perbedaan penting di antara keduanya.

Kualitas produk merupakan salah satu faktor yang mempengaruhi kepuasan pelanggan. Payne dalam (Hidayat, 2009) memberikan definisi kualitas produk adalah suatu bentuk dengan nilai kepuasan yang kompleks. Nasabah membeli jasa untuk memenuhi kebutuhannya dan nasabah akan memberikan nilai dalam proporsi terhadap kemampuan layanan untuk melakukan hal tersebut. Nilai yang diberikan pelanggan berhubungan dengan benefit atau keuntungan yang diterimanya. Kualitas produk didapatkan dengan cara menemukan keseluruhan harapan pelanggan, meningkatkan nilai produk atau pelayanan dalam rangka memenuhi harapan pelanggan tersebut.

Berdasarkan penelitian yang dilakukan oleh (Baiti, 2017)bahwa produk mempunyai pengaruh terhadap keputusan menjadi nasabah sedangkan penelitian yang di lakukan oleh (Muhidin, 2017) dan(Larasati, 2017) menyatakan bahwa produk tidak berpengauh terhadap minat menjadi nasabah. dan penelitian yang di lakukan oleh (Larasati, 2017) dan (Muhidin, 2017)menyatakan bahwa pelayanan berpengaruh terhadap minat menjadi nasabah. Bank Syariah adalah lembaga keuangan yang melaksanakan perantara keuangan dari pihak-pihak yang kelebihan dana kepada pihak-pihak lain yang membutuhkan berdasarkan prinsip-prinsip ajaran agama Islam, diantara prinsipprinsip tersebut yang paling utama adalah tidak diperkenankannya perbankan untuk meminta atau memberikan bunga kepada nasabahnya. Perbedaan prinsip antara Bank Konvensional dan Bank Syariah sangat jelas, terutama pada prinsip bunga yang terdapat pada bank konvesional. Bank syariah yang berdasarkan pada prinsip syariah Islam tidak mengenal adanya bunga, karena dianggap riba dan dilarang dalam Al-Quran an Sunnah(Shihab,2008).

Bank Syariah adalah lembaga keuangan yang melaksanakan perantara keuangan dari pihak-pihak yang kelebihan dana kepada pihak-pihak lain yang membutuhkan berdasarkan prinsip-prinsip ajaran agama Islam, diantara prinsipprinsip tersebut yang paling utama adalah tidak diperkenankannya perbankan untuk meminta atau memberikan bunga kepada nasabahnya. Perbedaan prinsip antara Bank Konvensional dan Bank Syariah sangat jelas, terutama pada prinsip bunga yang terdapat pada bank konvesional. Bank syariah yang berdasarkan pada prinsip syariah Islam tidak mengenal adanya bunga, karena dianggap riba dan dilarang dalam Al-Quran dan Sunnah (Shihab,2008).

Pada saat ini masyarakat yang memiliki ketertarikan menyimpan uangnya di bank pada dasarnya memenuhi kebutuhan dan kepuasannya. Dan Bank Muamalat berupaya untuk memberikan kualitas produknya dan pelayanannya sehingga meyakinkan para nasabah untuk menabung pada Bank Muamalat. Bank Muamalat memiliki beberapa produkproduk tanpa riba yang banyak diminati Nasabah Bank Muamalat, Salah satunya Tabungan iBMuamalat, Dari pengamatan penulis banyak sekali yang membuka tabungan tersebut.

Berdasarkan uraian di atas, maka penulis tertarik untuk melakukan penelitian dengan judul "Pengaruh Kualitas Produk dan Pelayanan Terhadap Keputusan Menjadi Nasabah Bank Muamalat Cabang Sorong".

\section{TINJAUAN PUSTAKA}

1. Kualitas Produk

Kualitas merupakan suatu istilah relatif yang sangat bergantung pada situasi. Ditinjau dari pandangan konsumen, secara subjektif orang mengatakan kualitas adalah sesuatu 
yang cocok dengan selera (fitness for use). Produk dikatakan berkualitas apabila produk tersebut mempunyai kecocokan penggunaan bagi dirinya. Pandangan lain mengatakan kualitas adalah barang atau jasa yang dapat menaikkan status pemakai. Ada juga yang mengatakan barang atau jasa yang memberikan manfaat pada pemakai (measure of utility and usefulness). Kualitas barang atau jasa dapat berkenaan dengan keandalan, ketahanan, waktu yang tepat, penampilannya, integritasnya, kemurniannya, individualitasnya, atau kombinasi dari berbagai faktor tersebut.

2. Pelayanan

Pengertian pelayanan ialah menolong untuk menyediakan segala sesuatu yang diperlukan oleh orang lain diataranya adalah pembeli. Pelayanan dapat diberikan kepada orang lain sebagai pertolongan yang dibutuhkan orang lain itu sendiri. Yang mana dengan pertolongan tersebut dapat membantu orang lain untuk bisa mengatasi masalahnya.

3. Keputusan

Keputusan adalah suatu reaksi terhadap beberapa solusi alternatif yang dilakukan secara sadar dengan cara menganalisa kemungkinankemungkinan dari alternatif tersebut bersama konsekuensinya. Setiap keputusan akan membuat pilihan terakhir, dapat berupa tindakan / opini. Itu semua bermula ketika kita perlu untuk melakukan sesuatu tetapi tidak tahu apa yang harus dilakukan. Untuk itu keputusan dapat dirasakan rasional atau irrasional dan dapat berdasarkan asumsi kuat atau asumsi lemah.

\section{METODE}

Penelitian ini dilaksanakan di Bank Muamalat Cabang Sorong berada di jalan Jendral Sudirman Kota Sorong.Waktu Penelitian ini dilaksanakan selama 3 (tiga) bulan yang dimulai dari bulan Mei 2020 Juli 2020.

$$
\text { Populasi dalam penelitian }
$$
populasinya adalah nasabah yang telah menabung di Bank Muamalat Cabang Sorong. Sedangkan sampel dalam penelitian ini diambil berdasarkan populasi yaitu berjumlah 44 responden. Sumber data yang digunakan adalah data primer yang berupa hasil penyebaran kuesioner yang harus dioleh menggunakan aplikasi SPSS 20.

\section{HASIL DAN PEMBAHASAN}

1. Pembahasan Hasil Penelitian

Berdasarkan hasil penelitian yang telah diuraikan sebelumnya menunjukkan bahwa terdapat pengaruh positif dan signifikan baik secara parsial maupun simultan kualitas produk dan pelayanan terhadap keputusan menjadi nasabahdi Bank Muamalat Cabang Sorong. Berikut ini dipaparkan penjelasan atas jawaban dari hipotesis penelitian.

a. Pengaruh Kualitas Produk (X1) Terhadap Keputusan (Y)

Berdasarkan hasil pengujian hipotesis pertama yang telah di lakukan,di ketahui bahwa hasil uji data menunjukkan bahwa terdapat pengaruh positif dan signifikan Kualitas Produk secara parsial terhadap Keputusan Menjadi Nasabah Bank Muamalat Cabang Sorong dengan nilai t hitung sebesar $8,030>t$ tabel sebesar 1,30204 dengan signifikansi $0,000<$ dari taraf signifikansi yaitu 0,05. Hal ini menunjukan bahwa terdapat pengaruh positif dan signifikan variable Kualitas Produk secara parsial terhadap Keputusan Menjadi Nasabah Bank Muamalat Cabang Sorong.

b. Pengaruh Pelayanan $\left(X_{2}\right)$ Terhadap Keputusan (Y)

Berdasarkan hasil pengujian hipotesis kedua yang telah di lakukan,di ketahui bahwa hasil uji data menunjukkan bahwa terdapat pengaruh positif dan signifikan Pelayanan secara parsial terhadap Keputusan Menjadi Nasabah Bank Muamalat Cabang Sorong dengan 
nilai t hitung di peroleh sebesar 1,857 $>\mathrm{t}$ table sebesar 1,30204 dengan signifikansi $0,000<$ dari taraf signifikansi 0,05. Hal ini menunjukan bahwa terdapat pengaruh positif dan signifikan variable Pelayanan secara parsial terhadap Keputusan Menjadi Nasabah Bank Muamalat Cabang Sorong.

c. Pengaruh Kualitas Produk $\left(X_{1}\right)$ dan Pelayanan (X2) Secara Simultan Terhadap Keputusan menjadi nasabahdi Bank Muamalat Cabang Sorong (Y)

Berdasarkan hasil pengujian hipotesis ketiga yang telah di lakukan,di ketahui bahwa hasil uji data menunjukkan bahwa terdapat pengaruh positif dan signifikan Kualitas Produk(X1) dan Pelayanan $(\mathrm{X} 2)$ secara simultan terhadap Keputusan Menjadi Nasabah(Y) pada Bank Muamalat Cabang Sorong dengan nilai $\mathrm{F}$ hitung di peroleh sebesar 91,704 > F tabel sebesar 3,22 dengan signifikansi 0,000 $<$ dari taraf signifikansi 0,05 . Ha ini menunjukkan bahwa terdapat pngaruh positifdan signifikan variable Kualitas Produk dan Pelayanan secara simultan terhadap Keputusan Menjadi Nasabah pada Bank Muamalat Cabang.

\section{PENUTUP}

\section{Kesimpulan}

Penelitian ini bertujuan untuk mengetahui Pengaruh Kualitas Produk Dan Pelayanan Terhadap Keputusan Menjadi Nasabah Bank Muamalat Cabang Sorong:

1. Kualitas Produk berpengaruh positif secara parsial terhadap Keputusan Menjadi Nasabah Bank Muamalat Cabang Sorong. Hal ini di buktikan dari nilai $\mathrm{t}$ hitung sebesar 8,303> $\mathrm{t}$ tabel 2,01954, dengan nilai signifikansi $0,000<$ 0,05 dan koefisien regresi sebesar 0.503 .

2. Pelayanan berpengaruh positif secara parsial terhadap Keputusan Menjadi Nasabah Bank Muamalat Cabang Sorong. Hal ini di buktikan dari nilai $t$ hitung sebesar 8,303> $\mathrm{t}$ tabel nilai signifikansi 2,01954 dengan signifikan sebesar 0,000<dari taraf signifikan yaitu 0,05 . Dan koefisien regresi mempunyai nilai positif sebesar 0,503.

3. Kualitas Produk dan Pelayanan berpengaruh positif secara simultan terhadap Keputusan Menjadi Nasabah Bank Muamalat Cabang Sorong. Hal ini di buktikan dari nilai $\mathrm{F}$ hitung sebesar 91,704 >F tabel sebesar 3,22 dengan signifikansi $0,000<$ dari tariff signifikan 0,05dan koefisienregresi mempunyai nilai positif sebesar 0,817

\section{Saran}

Berdasarkan hasil penelitian, pembahasan dan kesimpulan yang di peroleh, maka saran yang dapat di berikan untuk di jadikan sebagai bahan pertimbangan dalam meningkatkan Keputusan Menjadi Nasabah Pada Bank Muamalat Cabang Sorong dari dua variable yang telah di teliti adalah sebagai berikut :

1. Bagi Bank Muamalat Cabang Sorong

Pihak Bank agar lebih memaksimalkan strategi pemasarannya dalam usaha menarik nasabah yang baru dan mempertahankan nasabah yang lama. Sehingga mmpu meningkatkan kompetisi usaha yang baik dengan bank syariah lainnya baik bank syariah maupun bank konvensional.

2. Peneliti Selanjutnya

Berdasarkan hasil penelitian, pembahasan dan kesimpulan yang di peroleh,maka saran yang dapat di berikan untuk di jadikan sebagai bahan pertimbangan dalam meningkatkan Keputusan Menjadi Nasabah Pada Bank Muamalat Cabang Sorong dari dua variabel yang telah di teliti adalah sebagai berikut :

a. Bagi Bank Muamalat Cabang Sorong Pihak Bank agar lebih memaksimalkan strategi pemasarannya daam usaha menarik nasabah yang baru dan mempertahankan nasabah yang lama. Sehingga mampu meningkatkan kompetisi usaha yang baik dengan 
bank syariah lainnya baik bank syariah maupun bank konvensional.

b. Peneliti Selanjutnya

Sebaiknya

penelitian dengan jumlah

independent variable yang lebih banyak, sehingga dengan ditambahkannya independen variable diharapkan dapat diketahui bagaimana pengaruh keunggulankeunggulan lain terhaap keputusan menjadi nasabah.

\section{DAFTAR PUSTAKA}

Arikunto, S. (2006). Prosedur Penelitian Suatu Pendekatan Praktik. Jakarta: PT. Rineka Cipta.

Baiti, R. U. (2017). Pengaruh marketing mix terhadap keputusan menjadi nasabah tabungan ib muamalat di bank muamalat kcp salatiga. ekonomi.

Dibyantoro, d. (2012). Pengaruh Kualitas Pelayanan Terhadap Kepuasan. ekonomi dan bisnis.

Ghozali, I. (2016). Aplikasi Analisis Multivariete Dengan Program. Semarang: Universitas Diponegoro.

Haque, M. G., et al. (2021). Micro Financial Sharia Non-bank Strategic Analysis: a Study at BMT Beringharjo, Yogyakarta. Budapest International Research and Critics Institute (BIRCIJournal): Humanities and Social Sciences, 4(2), 1677-1686.

Hasan, M. I. (2002). Pokok-pokok Meteodologi Penilitian dan Aplikasinya. Bogor: Ghalia Indonesia.

Hidayat, A. (2009). Metode Penelitian Keperawatan dan Tekhnik. Analisis Data. Jakarta: Salemba Medika.

Larasati, F. (2017). Pengaruh religiusitas produk bank kepercayaan pengetahuan dan pelayanan terhadap referensi menabung pada perbankkan syariah. jurnal ekonomi.

Maddinsyah, A., et al. (2020). Desain Formulasi Dan Implementasi Bisnis Strategik Dengan Pendekatan Business Model Canvas (BMC) Terintegrasi Kerangka Integrated
Performance Management System (IPMS) Pada Koperasi Asperindo. Inovasi, 7(2), 67-76.

Muhidin. (2017). Pengaruh citra perusahaan, pengetahuan produk bank, kepercayaan dan pelayanan terhadap minat menjadi nasabah bank syariah dengan religiusan sebagai variabel moderating. jurnal ekonomi.

Nurjaya, N., et al. (2021). The Effect of Product Promotion and Innovation Activities on Marketing Performance in Middle Small Micro Enterprises in Cianjur. Budapest International Research and Critics Institute (BIRCIJournal): Humanities and Social Sciences, 4(1), 528-540.

Rasyid, N., \& Rawi, R. D. P. (2018). Pengaruh Bauran Pemasaran Terhadap Penjualan Pada Pt. Nestle Indofood Citarasa Indonesia Di Makassar. Sentralisasi, 7(2), 11-27.

Rawi, R. D. P., \& Lewenussa, R. (2019). Pengaruh Karakteristik Dan Kinerja Generation Young (Gen Y) Terhadap Ekspektasi Peluang Bisnis (Studi Kasus Di PT. Adira Group Kota Sorong). Gorontalo Management Research, 2(2), 80-89.

Sugiyono. (2014). Metode Penelitian Pendidikan Pendekatan Kuantitatif dan $R \mathcal{E D}$. Bandung: Alfabeta.

Sunarsi, D. (2020). Pengaruh Bauran Pemasaran Dan Kualitas Pelayanan Terhadap Kepuasan Konsumen Pada Giant Dept Store Cabang BSD Tangerang. E-Mabis: Jurnal Ekonomi Manajemen dan Bisnis, 21(1), 7-13.

Tjiptono, F. (2008). Strategi Pemasaran. yogjakarrta: Edisi 3.

Wangsi, M. M., \& Rawi, R. D. P. (2018). Perlindungan Konsumen Dalam Pelabelan Produk Menurut Ekonomi Islam. Sentralisasi, 7(1), 1-9.

Yusuf, A., \& Sunarsi, D. (2020). The Effect of Promotion and Price on Purchase Decisions. Almana: Jurnal Manajemen dan Bisnis, 4(2), 272-279. 